I NRA Prod. Anim., 2001, 14 (4 ), 219-230
K. BIGOT, S. TESSERAUD, M. TAOUIS, M. PICARD

INRA, Stati on de Recherches Avi coles, 37380 Nouzilly

Courriel : bi got@tours.inra.fr

\section{Alimentation néonatale et développement précoce du poulet de chair}

Dans la pratique, les poussins ne sont alimentés que 10 à 60 heures après leur éclosion. Pourtant, le développement est intense pendant les premiers jours de vie et le résidu vitellin ne représente qu'une petite réserve de nutriments. Retarder la fourniture d'aliments peut affecter la croissance ultérieure des poussins et amoindrir leurs capacités de défense contre les agents pathogènes.

La sélection génétique et la maîtrise de l'alimentation et des conditions sanitaires ont contribué à accélérer la vitesse de croissance des poulets de chair. La première semaine de

\section{Résumé}

Depuis une dizaine d'années, l'alimentation du poussin nouveau-né suscite un intérêt croissant car elle influence, à terme, les performances des poulets de chair. La résorption rapide du résidu vitellin représente une réserve relativement modeste de nutriments ( 1 jour) par rapport au développement intense du tube digestif et de ses fonctions d'une part et du muscle pectoral d'autre part pendant les deux ou trois premiers jours de la vie. Le délai d'alimentation dû aux conditions d'éclosion et de transport peut varier d'un individu à l'autre de 10 à 60 heures. Plusieurs travaux concluent que ce jeûne, à un moment critique du développement, retarde de manière irréversible la croissance et réduit sans doute les capacités de défense immunologique du poussin. De plus, les rares travaux portant sur la composition des régimes alimentaires pour très jeunes poussins suggèrent que les rations couramment distribuées sont peut être trop pauvres en protéines et trop riches en lipides. II est, par ailleurs, nécessaire de freiner la croissance entre une et trois semaines d'âge pour limiter les problèmes locomoteurs et métaboliques ultérieurs. Les recherches actuelles s'orientent vers un "pilotage" plus précis de la nutrition des jeunes poulets de chair en stimulant le développement initial au cours de la première semaine, puis en le freinant, avant d'optimiser économiquement l'alimentation après l'âge de trois semaines. Dans un tel schéma général, les effets de stimulations initiales du développement des poussins par une alimentation plus précoce ou/et mieux adaptée sur la qualité de la viande et les performances globales de l'élevage restent à quantifier avec précision. vie des poussins représente aujourd'hui presque $20 \%$ de la durée de vie d'un poulet de chair, c'est-à-dire d'un poulet à croissance rapide actuellement abattu vers 39-40 jours à un poids vif de $2 \mathrm{~kg}$ environ. Durant cette période, le poids des poussins augmente considérablement (Nitsan et al 1991a, Chamblee et al 1992). Pour des raisons pratiques liées à l'accouvage et au transport des animaux, les poussins ne sont alimentés que 10 à 60 heures après leur naissance. Les conséquences de ce délai initial et des conditions de développement précoce sur la qualité ou les rendements en viande à 6 ou 7 semaines sont mal connues. L'alimentation des poussins au cours des premiers jours de vie ne se limite pas à promouvoir un bon départ de croissance. Le retard ou le défaut d'apport alimentaire affecte également la résistance et la sensibilité des animaux aux agents pathogènes.

La première partie de cet article décrit les principales modifications physiologiques, digestives et métaboliques survenant chez le poussin durant la première semaine de vie. Puis la seconde partie examine les influences que peut avoir l'alimentation au cours de cette période sur le développement des poulets. 


\section{1 / Particularités de la première semaine de vie du poussin}

\section{1 / Croissance}

Le poids vif du poussin double au cours des cing premiers jours de la vie (tableau 1). La vitesse de croissance des poussins exprimée proportionnellement au poids vif $(\mathrm{g} / \mathrm{j} / 100 \mathrm{~g}$ de poids vif) atteint son maximum entre 3 et 5 jours d'âge (Murakami et al 1992). Leur consommation journalière augmente linéairement avec l'âge. A l'âge de deux jours, le poussin consomme quotidiennement environ $10 \mathrm{~g}$ d'aliment contre $35 \mathrm{~g}$ cinq jours plus tard.

\section{2 / Utilisation du résidu vitellin}

Le sac vitellin, qui contient les nutriments non utilisés au cours du développement embryonnaire, est internalisé dans la cavité abdominale à partir du 19ème jour d'incubation. II est classiquement considéré comme une réserve pouvant couvrir temporairement les besoins de survie du poussin nouveau-né (Nitsan et al 1991b, Noy et al 1996). A la naissance, le sac vitellin pèse environ $8 \mathrm{~g}$ ce qui représente $17 \%$ du poids du poussin (tableau 1). La résorption de son contenu a lieu en grande partie pendant les 48 premières heures de vie avec une réduction de $50 \%$ de son poids. Au bout de 4 à 5 jours de vie, il est résorbé en quasi totalité (Noble et Ogunyemi 1989, Nitsan et al 1991b, Chamblee et al 1992, Sklan et Noy 2000). L'utilisation, après l'éclosion, du contenu vitellin par le poussin s'effectue de deux manières. Il s'agit à la fois d'un passage dans la circulation sanguine via les membranes du sac vitellin, perméables entre autres aux lipides, et d'un transfert du contenu du sac vitellin vers l'intestin par le canal de Meckel (Noy et al 1996, Noy et Sklan 1998a et b).

A la naissance, le liquide vitellin est essentiellement composé d'eau (46\%), de lipides ( $30 \%$, sous la forme de phospholipides et triglycérides) et de protéines (20\%) (Applegate et Lilburn 1996, Puvadolpirod et al 1997) La dégradation du contenu vitellin est censée fournir l'énergie nécessaire à la survie du poussin nouveau-né dans le cas où celui-ci ne recevrait aucun apport extérieur d'aliment. Un gramme de lipides fournit 8 à 9 kcal d'énergie métabolisable. En considérant les lipides comme la principale source d'énergie contenue dans le vitellus, leur conversion totale en énergie fournirait au poussin une réserve de $20 \mathrm{kcal}$. Le besoin d'entretien d'un poussin de $40 \mathrm{~g}$ est d'environ $25 \mathrm{kcal}$ par jour d'après I'équation 2,2 kcal / ( $g$ de poids vif) ${ }^{2 / 3}$ de Hurwitz et al (1980). De plus, pendant cette période, l'énergie requise par le poussin doit couvrir à la fois les besoins pour son métabolisme de base (respiration, digestion par exemple) et pour sa croissance. L'apport d'aliment aussi tôt que possible est alors essentiel afin de minimiser la perte de poids post éclosion du poussin due au déficit énergétique. Dans une perspective de croissance optimale, le contenu vitellin ne semble représenter qu'une réserve nutritionnelle très marginale par rapport à l'alimentation exogène.

Au-delà de son rôle de réserve de nutriments, le résidu vitellin semble être impliqué dans le processus d'initiation du développement corporel du poussin. Durant les 5 premiers jours de vie, il existe une corrélation négative $(r=-0,71 ; P<0,01)$ entre le poids vif du poussin et le poids du résidu vitellin (Chamblee et al 1992). De plus, la résorption vitelline débute immédiatement après la naissance alors que l'amorce de la croissance corporelle réelle du poussin est différée d'environ 24 heures (tableau 1). Enfin, I'ablation du sac vitellin à la naissance décale l'initiation de la croissance de 2 jours (Murakami et al 1992, Turro et al 1994) et le poids vif des poussins est alors réduit de $13 \%$ à l'âge de 5 jours (Chamblee et al 1992).

Le résidu vitellin apparaît donc comme une réserve de nutriments quantitativement modeste. Néanmoins, son utilisation en association avec le développement du tractus digestif semble essentielle pour initier l'adaptation à une alimentation exogène.

Tableau 1. Évolution du poids vif, du poids du résidu vitellin et du poids relatif $d u$ résidu vitellin chez le poussin nouveau-né (moyennes \pm SEM, 25 animaux par groupe). Adapté de Chamblee et al (1992).

Les poussins sont placés en parquet 12 heures après l'éclosion. Ils reçoivent ad libitum de l'eau et un aliment démarrage (3047 kcal/kg d'énergie métabolisable, $201 \mathrm{~g}$ de protéines/kg).

\begin{tabular}{|c|c|c|c|}
\hline Temps post-éclosion (h) & Poids vif $(\mathrm{g})$ & Poids du sac vitellin $(\mathrm{g})$ & $\begin{array}{c}\text { Poids relatif du sac vitellin } \\
\text { (g/100 g de poids vif) }\end{array}$ \\
\hline 0 & $47,0 \pm 0,6^{\mathrm{e}}$ & $7,9 \pm 0,2^{\mathrm{a}}$ & $16,8 \pm 0,4^{\mathrm{a}}$ \\
12 & $45,8 \pm 0,5^{\mathrm{e}}$ & $7,3 \pm 0,2^{\mathrm{a}}$ & $15,9 \pm 0,4^{\mathrm{a}}$ \\
24 & $46,7 \pm 0,7^{\mathrm{e}}$ & $6,4 \pm 0,3^{\mathrm{b}}$ & $13,6 \pm 0,3^{\mathrm{b}}$ \\
48 & $53,2 \pm 0,7^{\mathrm{d}}$ & $3,6 \pm 0,2^{\mathrm{c}}$ & $6,6 \pm 0,4^{\mathrm{c}}$ \\
72 & $59,6 \pm 1,0^{\mathrm{c}}$ & $1,9 \pm 0,2^{\mathrm{d}}$ & $3,2 \pm 0,4^{\mathrm{d}}$ \\
96 & $71,3 \pm 1,1^{\mathrm{b}}$ & $1,3 \pm 0,1^{\mathrm{e}}$ & $1,8 \pm 0,2^{\mathrm{e}}$ \\
120 & $81,9 \pm 1,6^{\mathrm{a}}$ & $0,9 \pm 0,1^{\mathrm{e}}$ & $1,2 \pm 0,1^{\mathrm{e}}$ \\
\hline
\end{tabular}

Dans une colonne, les valeurs suivies de lettres différentes sont significativement différentes à $P<0,05$. 


\section{3 / Développement du tractus digestif}

Les espèces aviaires sélectionnées sur le critère d'une vitesse de croissance élevée présentent un développement précoce du système digestif (Lilja 1983, Jin et al 1998). Inversement, la croissance des organes digestifs est lente chez les volailles sélectionnées pour la ponte (Nir et al 1993). Le développement du tractus gastro-intestinal est un phénomène prioritaire dans le développement général du poussin. Ainsi, durant les 4 premiers jours de vie, un quart des protéines absorbées est retenu par l'intestin (Noy et Sklan 1999b).

Chez le poussin nouveau-né, les processus de digestion et d'absorption sont peu efficaces et le passage soudain a une alimentation exogène solide s'accompagne d'un développement rapide du système gastro-intestinal et des organes annexes impliqués dans le processus de digestion (gésier, pancréas, foie). Les modifications qui surviennent sont à la fois des modifications morphologiques du tube digestif (croissance allométrique des organes) et une maturation des capacités digestives du poussin (adaptation, en fonction de l'ingéré, de la sécrétion des enzymes intestinales et pancréatiques permettant la dégradation des nutriments en particules assimilables, augmentation des capacités d'absorption de ces particules).

La taille et le poids des trois principales portions de l'intestin (duodénum, jéjunum, iléum) et des organes annexes (foie, pancréas, gésier, proventricule) augmentent significativement durant la première semaine de vie du poussin (Uni 1999, Uni et al 1999 ; figure 1). Néanmoins, chaque organe et chaque portion de l'intestin se caractérise par une vitesse de croissance propre (Nitsan et al 1991a, Nir et al 1993, Noy et Sklan 1998c, Uni et al 1998 et 1999. Uni 1999). La vitesse de croissance des trois segments intestinaux et des organes annexes, exprimée proportionnellement au poids vif, est maximale entre 6 et 7 jours après la naissance. Toutefois, la croissance allométrique du pancréas (figure 1), du duodénum et du jéjunum (Uni et al 1999) est plus rapide et plus précoce que celle du foie ou de l'iléum. D'une manière générale, le développement du système gastro-intestinal se déroule à une vitesse largement supérieure à celle du corps entier (Sell et al 1991, Pinchasov et Noy 1994, J in et al 1998) ou d'organes essentiels au développement comme le cœur ou les poumons, par exemple (Nitsan et al 1991a).

A la naissance, le poussin dispose d'une faible réserve d'enzymes pancréatiques (trypsine, chymotrypsine, amylase et lipase) synthétisées durant la vie embryonnaire (Dibner 1997). Leur sécrétion est stimulée de façon significative dès la première semaine de vie. La mesure de la sécrétion totale d'azote, reflet de la sécrétion enzymatique totale, est multipliée par deux entre 4 et 7 jours d'âge (Noy et Sklan 1995, Uni et al 1995b). La synthèse et l'activité de ces enzymes ont été déterminées dans le pancréas mais ces données donnent peu d'information sur les capacités digestives réelles
Figure 1. Evolution du poids et croissance allométrique du pancréas, de l'intestin grêle et du foie chez le poussin nouveau-né (moyennes de 3 animaux par mesure). Adapté de Nitsan et al $1991 a$.

Les poussins sont placés 3 par cage à l'âge d'un jour. Ils accèdent librement à de l'eau et un aliment démarrage commercial (2990 kcal EM/kg, $210 \mathrm{~g}$ protéines $/ \mathrm{kg}$ ).
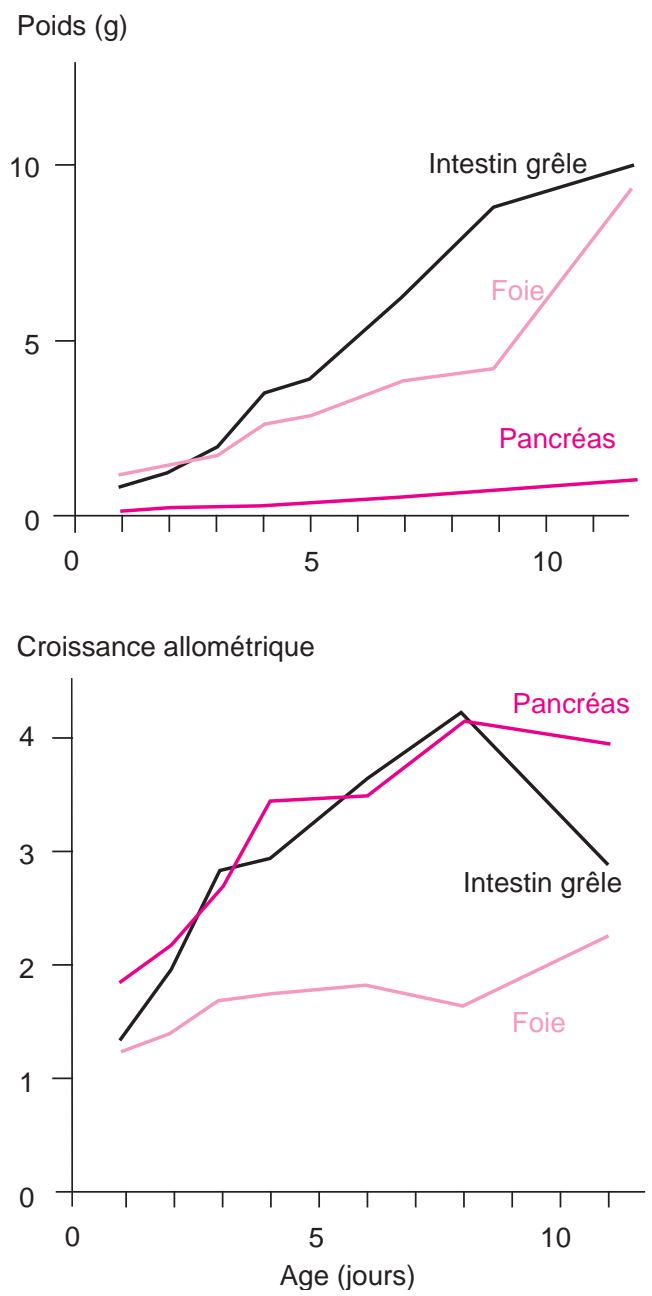

du poussin. En effet, ces enzymes doivent être présentes et actives dans l'intestin pour agir sur la digestion. La mesure des activités enzymatiques dans l'intestin (Nitsan et al 1991a et $1991 b$; figure 2) montre que chaque enzyme présente son propre profil de stimulation. L'activité amylasique augmente dès la naissance, mais reste toutefois négligeable jusqu'à l'âge de 2 jours. Ce n'est qu'entre 2 et 7 jours d'âge qu'il est mesuré une augmentation rapide et importante de cette activité. Ceci serait probablement lié à la quasi absence de glucides dans le liquide vitellin ; le délai correspondrait à l'adaptation des sécrétions aux nutriments ingérés par le poussin. La présence de lipides et de protéines dans le liquide vitellin permettrait une sécrétion et donc une activité intestinale plus précoce des enzymes de dégradation de ces nutriments. On observe un pic de l'activité de la trypsine aux alentours de 4 jours d'âge et l'activité lipasique augmente régulièrement dès I'éclosion (figure 2 ). II semble donc que l'âge et l'état nutritionnel du poussin soient deux paramètres influençant la sécrétion et l'activité des enzymes pancréatiques (Sklan et Noy 2000). 
Figure 2. Activités (unités/kg de poids vif) de la trypsine, de la chymotrypsine, de l'amylase (mesurées par spectrométrie) et de la lipase (mesure enzymologique) dans le contenu intestinal chez le poussin nouveau-né (moyennes de 3 animaux). Adapté de Nitsan et al 1991a.
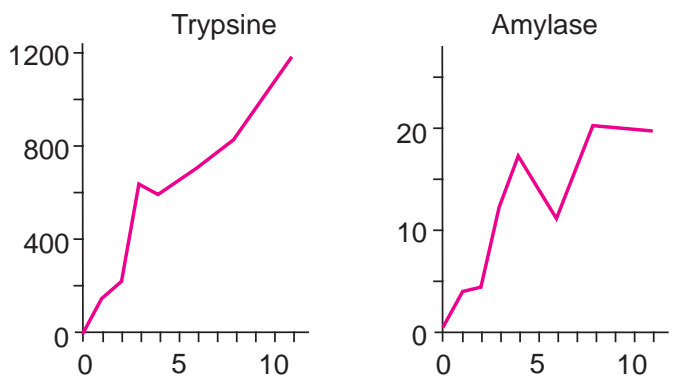

Les capacités digestives du poussin a ugmentent rapidement après l'éclosion.

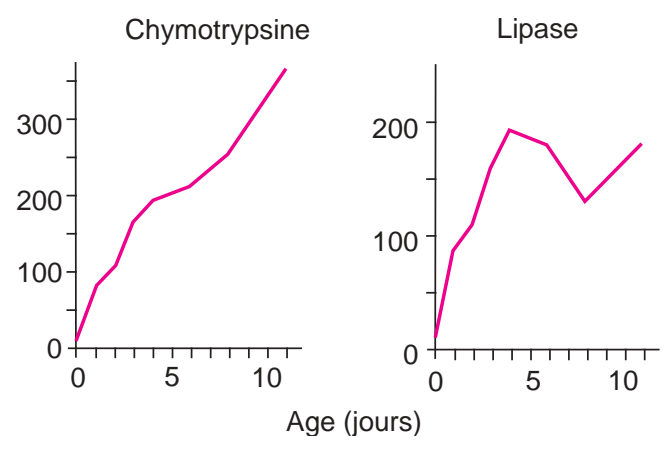

L'augmentation de la capacité d'absorption des nutriments est liée à deux événements distincts : le développement des muqueuses intestinales et la mise en place de systèmes de transport transmembranaire actifs. La prolifération des muqueuses résulte de I'hyperplasie cellulaire et conduit à l'augmentation de la surface d'absorption et à celle du poids de l'intestin (Moran 1985, Uni et al 1995a, Dibner 1997,
Noy et Sklan 1997, Uni 1999). Au cours de la première semaine de vie, les villosités intestinales se développent en hauteur et en largeur et le nombre d'entérocytes par villosité est augmenté (Dibner et al 1996). Toutefois, ces modifications sont fonction de l'âge et de la région de l'intestin considérée. Le développement des villosités est plus marqué dans le duodénum que dans l'iléum et le jéjunum (figure 3). L'augmentation du volume des villosités et de la densité des entérocytes dans le duodénum se limite aux 4 jours qui suivent l'éclosion alors qu'elle se poursuit jusqu'au dixième jour de vie dans le jéjunum et l'iléum (Uni et al 1998).

La capacité d'absorption des nutriments dans l'intestin et, plus précisément, dans le duodénum et le jéjunum, principaux sites d'absorption chez le poulet, augmente également avec l'âge. Sachant que le glucose et un grand nombre d'acides aminés sont absorbés par un co-transport Na-dépendant, la mesure de l'activité $\mathrm{Na}^{+}, \mathrm{K}^{+} \mathrm{ATP}$ asique, décrite récemment par Sklan et Noy (2000), représente un bon indicateur de l'absorption par les muqueuses intestinales. Cette activité est particulièrement augmentée durant les 4 premiers jours de vie (figure 4). Le poussin de 4 jours est par exemple capable d'absorber plus de $80 \%$ du glucose, de la méthionine et de l'acide oléique consommés (Noy et Sklan 1996).

L'augmentation de la digestibilité apparente des différents nutriments est le reflet de ces diverses modifications qui conduisent à la maturation du système digestif pendant la première semaine de vie du poussin. A 4 jours, la digestibilité intestinale apparente des protéines atteint $78 \%$ alors qu'elle avoisine déià 85 $\%$ pour l'amidon et les lipides (Noy et Sklan 1995, 1997 et 1998a; Uni et al 1995b). Au-delà, les capacités digestives évoluent relativement

Figure 3. Volume des villosités intestinales et nombre d'entérocytes par villosité chez le poussin nouveauné (moyenne des valeurs obtenues sur 10 villosités adjacentes pour 5 animaux). Adapté de Uni et al 1998. Les poulets reçoivent un aliment démarrage commercial 4 heures après l'éclosion.
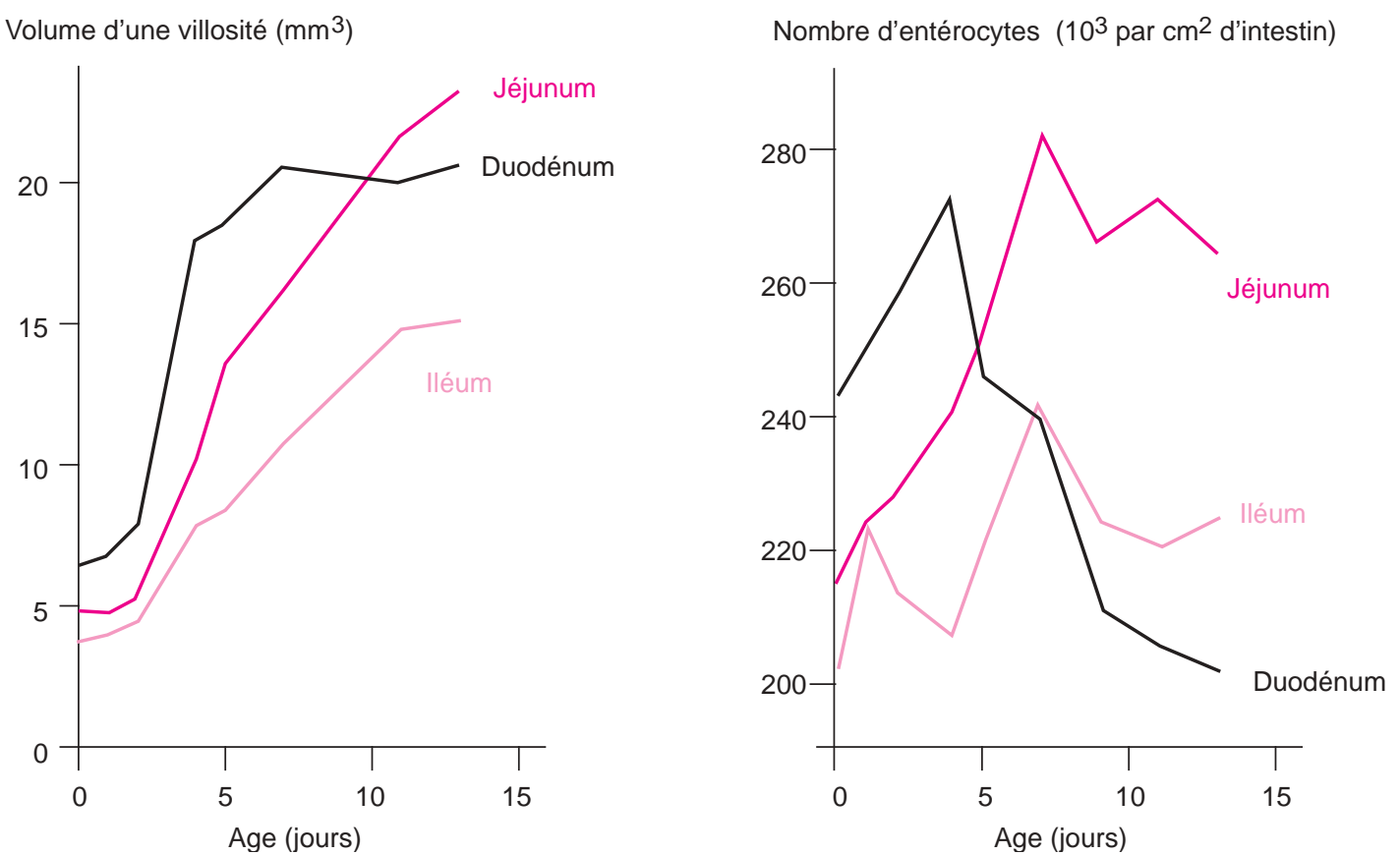
moins vite ce qui souligne l'importance de la première semaine de vie dans la mise en place des fonctions digestives et son impact ultérieur sur la croissance musculaire des poulets.

Figure 4. Activité $\mathrm{Na}^{+}, \mathrm{K}^{+}$ATPasique intestinale chez le poussin nouveau-né (moyenne de 6 animaux). Adapté de Sklan et Noy 2000.

Les poussins reçoivent un aliment démarrage classique immédiatement après l'éclosion. Le dosage de l'activité $\mathrm{Na}^{+}, \mathrm{K}^{+}$ATPasique est réalisé selon la technique décrite par Del Castillio et al (1991).

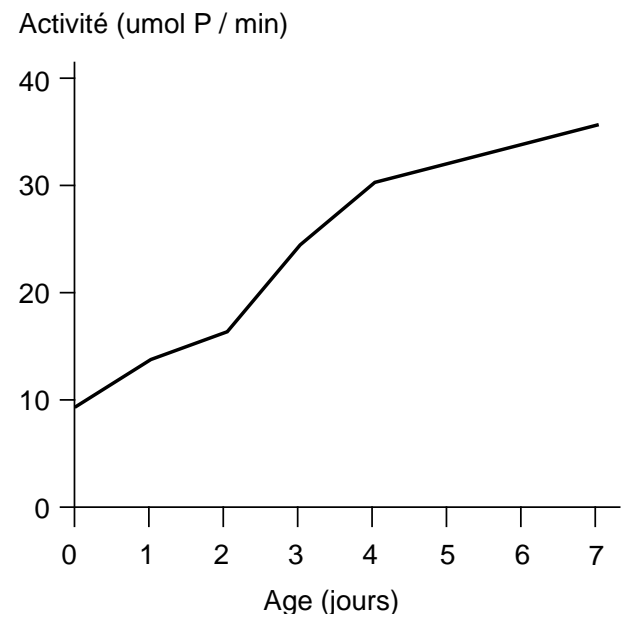

\section{4 / Développement musculaire}

Les espèces aviaires sélectionnées sur le critère d'une vitesse de croissance élevée se caractérisent par un développement musculaire important dès la première semaine de vie (Moss 1968). Ainsi, le poids relatif des muscles squelettiques et plus précisément du muscle pectoral est multiplié par deux entre 1 et 5 jours après l'éclosion (Halevy et al 2000). Les gains de poids des muscles pectoraux et des muscles de la patte correspondent, respectivement, à une semaine d'âge, à $6 \%$ (Kang et al 1985, Halevy et al 2000) et $2 \%$ du poids vif (Kang et al 1985).

Les fibres musculaires se mettent en place progressivement au cours de la vie embryonnaire (Romanoff 1960) et leur nombre final est fixé à la naissance. Les modifications post éclosion concernent la taille de la fibre musculaire (développement longitudinal et radial) et le nombre de noyaux par fibre. La croissance musculaire implique principalement les cellules satellites. Celles-ci sont en proportions importantes près de la fibre musculaire chez le poussin nouveau-né de type chair (Ricklefs 1985, Mitchell et Burke 1995, Duclos et Rémignon 1996). Les cellules satellites ont la capacité de se multiplier et de fusionner avec les fibres musculaires. Elles augmentent ainsi le nombre de noyaux par fibre et, par conséquent, le potentiel de synthèse de protéines musculaires. Le nombre de cellules satellites évolue en fonction de l'âge (Duclos et al 1996) et de récents travaux montrent une augmentation significative du nombre de cellules satellites par gramme de muscle pectoral jusqu'à l'âge de 3 jours suivie d'une baisse entre 4 et 5 jours (Halevy et al 2000 ; figure 5)

Parallèlement, la capacité de ces cellules à proliférer est intense au cours des 2 premiers jours de vie, puis elle décline progressivement (Goddard et al 1996, Halevy et al 2000 ; figure 5).

Figure 5. Evolution du nombre de cellules satellites par gramme de muscle pectoral et de leur capacité à proliférer chez le poussin nouveau-né (moyennes de 6 animaux dans trois expériences indépendantes). Adapté de Halevy et al 2000.

Les poulets reçoivent un aliment démarrage classique une heure après l'éclosion. Les cellules satellites sont préparées à partir du muscle pectoral prélevé selon la technique décrite par Halevy et Lerman (1993).

Nombre de cellules satellites / $\mathrm{g}$ de muscle pectoral

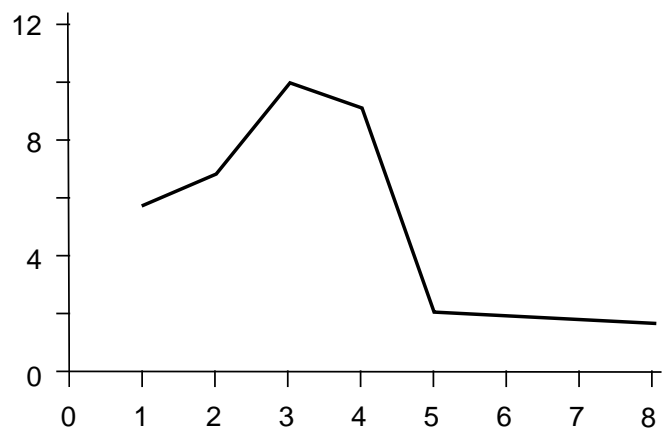

Capacité à proliférer

(quantité (dpm) de thymidine marquée incorporée dans l'ADN)

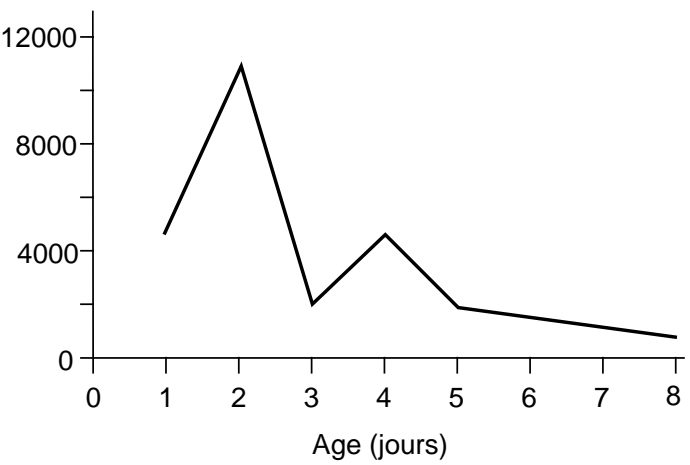

Les processus de développement et de maturation des fibres musculaires, importants chez le poulet de chair, sont extrêmement précoces, limités dans le temps et les deux premiers jours de vie semblent être une période cruciale pour le développement musculaire du poussin. Les implications de ce développement initial sur la production de viande ulterieure sont encore mal connues et justifient l'attention particulière qui doit être portée à l'alimentation lors des tout premiers instants de la vie des poussins. Notons toutefois qu'au-delà de la première semaine de vie, le muscle continue à croître, à accumuler des noyaux et à se différencier d'un point de vue métabolique et contractile (Moss 1968).

Le développement très rapide des activités digestives et des fibres musculaires après la naissance pose le problème de la répartition des ressources alimentaires entre des fonctions prioritaires pour la survie et le développement des poussins (Siegel et Dunnington 
1998). Parmi ces fonctions le développement du système immunitaire peut-il être pénalisé par une pression de sélection trop forte sur la croissance musculaire?

\section{5 / Mise en place du système immunitaire}

Comme chez les mammifères, il existe chez les oiseaux des organes lymphoïdes primaires (bourse de Fabricius et thymus) et secondaires (rate, diverticule de Meckels, glande de Harderian, plaques de Peyer et amygdale caecale). Ces tissus sont mis en place et colonisés par les cellules lymphoïdes au cours de la vie embryonnaire (Romanoff 1960). A la naissance, le système immunitaire est immature (Dibner et al 1998b). Le poussin nouveau-né est inapte à répondre efficacement, en terme de production de cellules immunitaires et d'anticorps, aux agents pathogènes ou à l'injection de la plupart des vaccins. Le système immunitaire, à la différence du système digestif décrit précédemment, évolue lentement pendant la première semaine de vie.

Le développement de la bourse de Fabricius occupe une place prépondérante dans la mise en place de la réponse immunitaire chez les oiseaux (Sayegh et al 2000). Le poids de la bourse de Fabricius n'est que de 0,05 g à la naissance alors qu'il atteint en moyenne 0,16 g à 8 jours d'âge (Dibner et al 1998b). Cette vitesse de croissance est maintenue pendant plusieurs semaines. L'augmentation du poids de la bourse de Fabricius est due à la multiplication des lymphocytes $B$, cellules sécrétrices d'immunoglobulines. Pourtant, la réponse humorale du très jeune poussin est principalement de type passive. Elle dépend des immunoglobulines maternelles de classe $\mathrm{G}$ déposées dans le résidu vitellin (Leslie 1975) et de l'expression en début de vie d'immunoglobulines de classe $M$ à la surface de la bourse de Fabricius. L'analyse histochimique de coupes de bourses de Fabricius de poussins âgés d'un jour montre qu'ils sont incapables de synthétiser les immunoglobulines de classes $G$ et A (Whittow 1999). L'ablation de la bourse de Fabricius chez des poussins nouveau-nés conduit à une réponse humorale défectueuse des animaux pendant le reste de leur vie (Perey et Bienenstock 1973), ce qui traduit bien son implication dans la mise en place de la réponse immunitaire. Notons toutefois que l'efficacité de la réponse humorale ne dépend pas uniquement des capacités de sécrétion des immunoglobulines dont le pouvoir protecteur est lui-même lié à leur migration par voie sanguine vers les muqueuses (digestives et respiratoires), principales voies de pénétration des agents pathogènes.

Enfin, le développement du système immunitaire pendant la première semaine de vie dépend étroitement de l'environnement du poussin. L'exposition du poussin aux antigènes stimule les processus de prolifération et de différenciation des différents clones de cellules immunitaires (Whittow 1999).

La sélection génétique sur le critère d'une vitesse de croissance élevée a eu un impact négatif sur le plan immunologique. Les poulets de chair sont moins résistants aux agents pathogènes et, plus précisément, leur capacité a produire des anticorps (réponse humorale à médiation cellulaire) s'est amoindrie au cours de générations successives (Qureshi et Havenstein 1994).

\section{2 / Alimentation post éclo- sion et développement du poussin}

S'il existe une compétition entre différentes fonctions pour l'utilisation des ressources alimentaires comme le suggèrent Siegel et Dunnington (1998) et que cette situation est en grande partie la conséquence du choix des critères de sélection génétique, une réflexion sur les conditions optimales d'alimentation s'impose pour les génotypes actuels. La première semaine de vie est une période relativement mal connue sur le plan nutritionnel. Les nutritionnistes de la pratique ont longtemps sousestimé l'importance de cette période pendant laquelle le poussin consomme une quantité d'aliment économiquement négligeable.

Période critique de développement tissulaire, les premiers jours de la vie du poussin sont également une phase de transition d'un métabolisme utilisant principalement les lipides et les protéines du vitellus vers une alimentation dominée par les glucides. De nombreux aspects de la nutrition des jeunes poussins mériteraient une discussion. Après avoir brièvement fait le point sur certains aspects de la composition de l'aliment et des pratiques de restriction alimentaire, nous insisterons ici plus particulièrement sur le délai d'alimentation appliqué après la naissance du poussin car il s'agit d'un point important dans les pratiques d'élevage actuelles.

\section{1 / E ffets de la composition de l'aliment}

Les tables de I'INRA (Larbier et Leclerca 1991) et du NRC (1994) recommandent pour un aliment 'démarrage' destiné au poulet de chair de 0 à 3 semaines d'âge, une concentration énergétique avoisinant $3200 \mathrm{kcal} / \mathrm{kg}$ et une concentration protéique de 22 ou $23 \%$. Un tel équilibre suppose un apport conséquent de lipides alimentaires (environ $10 \%$ de l'aliment). Dibner et al (1998a) ont testé différentes combinaisons de formulation de l'aliment apporté pendant les 2 premiers jours de vie à des poussins et ont suivi leur courbe de croissance jusqu'à l'âge de 41 jours. La croissance et l'efficacité alimentaire optimales ont été paradoxalement obtenues avec un aliment composé de $50 \%$ de protéines et de $50 \%$ de glucides sans apport de lipides. Le passage à une alimentation exogène et le développement du tube digestif, décrit dans le chapitre précédent, s'accompagnent d'une sécrétion limitante de sels biliaires (Krogdahl 1985) et d'une faible production de lipase pancréatique (Nir et al 1993). Ces conditions expliquent que les lipides n'aient une influence sur la croissance qu'à partir de l'âge d'environ 10 jours (Chamblee et al 1992). Or, la plupart des aliments commer- 
ciaux destinés aux jeunes poussins sont dérivés de travaux portant sur des poulets plus âgés et ne sont pas, sur le plan nutritionnel, reellement adaptés au très jeune âge (Lilburn 1998). Néanmoins, les résultats de Dibner et al (1998a) soulèvent plusieurs questions. Est-ce la composition de l'aliment apporté pendant les 48 premières heures qui influence à elle seule et à long terme les performances de croissance? ou bien l'amélioration des performances est-elle due à une interaction entre le délai d'alimentation réduit après la naissance et le régime testé ?

La recherche de stimulations de la croissance précoce semble également contradictoire en première analyse avec les pratiques qui visent à la réduire pour limiter l'apparition ultérieure de troubles locomoteurs ou d'ascites chez les poulets à croissance rapide (Sanchez et al 2000). Notons que l'apparition de ces troubles est étroitement liée à la vitesse de croissance (Nir 1998). Ainsi, la réduction de la croissance entre 1 et 3 semaines d'âge favoriserait le développement du squelette et améliorerait la qualité de l'os aux dépens du développement de tissus tels que le muscle, ce qui limiterait, par exemple, les risques de déformations des pattes.

\section{2 / E ffets de la restriction ali- mentaire}

La restriction alimentaire consiste à limiter le niveau de consommation d'un aliment en temps ou en quantité. Cette pratique est utilisée en élevage pour diverses raisons : diminution du taux de graisse de la carcasse (Plavnik et Hurwitz 1985, Plavnik et al 1986), amélioration de l'efficacité alimentaire, réduction de la fréquence des pathologies associées à une vitesse de croissance élevée telles que les ascites (Acar et al 1995, J ones 1995, Sanchez et al 2000) ou les troubles locomoteurs (Scheideler et Baughman 1993).

Trois types de restrictions alimentaires sont pratiquées : la restriction quantitative d'aliment (Plavnik et al 1986, Zulkifli et al 1994), la dilution énergétique du régime par des fibres (Leterrier et Constantin 1996, Leterrier et al 1998, Picard et al 1999) et la réduction de la durée d'éclairement (Lott et al 1996). En fait la plupart des programmes pratiques de restriction alimentaire débutent après plusieurs jours de vie (poussins âgés d'une semaine) et n'interviennent pas réellement dans la croissance initiale. De plus, ce mode d'alimentation, lorsqu'il est appliqué très précocement, n'est pas particulièrement bénéfique sur les performances à long terme des poulets. En effet, les poussins compensent la perte de poids induite par une restriction transitoire et ont un poids à l'abattage similaire à celui des animaux non restreints (Plavnik et al 1986, Ballay et al 1992, J ones 1995, Zubair et Leeson 1996). Toutefois, la réduction de l'apport énergétique affecte le développement des organes de manière variable selon le tissu considéré ; par exemple, le développement du cœur et du foie semble plus retardé que celui du gésier ou de la bourse de Fabricius (J ones 1995). La dilution énergétique ne permet pas de stimuler efficace- ment le développement du tube digestif (Picard et al 1999) ni d'améliorer la qualité de I'os (Leterrier et al 1998).

II semble établi qu'une restriction alimentaire modérée, par réduction de la durée d'éclairement ou de l'apport énergétique entre 1 et 3 semaines d'âge, est un moyen efficace de réduire les troubles pathologiques associés à une croissance rapide. Néanmoins, afin de ne pas pénaliser le développement du poussin, la stratégie en pratique serait au préalable de stimuler la croissance initiale pour que l'animal puisse exprimer, après cette période de restriction, tout son potentiel de croissance musculaire, ses capacités digestives et immunitaires. Cette première étape de stimulation initiale concerne notamment la durée du délai d'alimentation que subit le poussin après l'éclosion.

\section{3 / E ffets du délai d'alimentation}

Le délai d'alimentation correspond au temps écoulé entre l'éclosion du poussin et le premier apport d'aliment. Dans la pratique, le premier apport d'aliment et d'eau a lieu de 10 à 60 heures après l'éclosion. Ce délai correspond globalement au temps que les poussins passent dans l'éclosoir avant leur expédition, auquel il faut y ajouter le temps de transport des animaux vers les élevages. Pendant ce délai, le résidu vitellin est une source de nutriments disponibles qui ne couvre que très partiellement les besoins des animaux. Or, le niveau alimentaire des poussins, c'est-à-dire la quantité d'aliment consommée pendant la première semaine de vie, a des conséquences majeures sur leur vitesse de croissance (F anguy et al 1980) et les performances zootechniques des poulets en sont affectées à terme.

En montrant qu'une intubation de divers nutriments à des poulets de chair à la naissance avait des conséquences positives sur leur croissance, Noy et Pinchasov (1993) suggéraient déjà l'importance de la durée du délai d'alimentation sur la croissance du poussin nouveau-né et sur les différentes étapes de son développement.

La perte de poids causée par un jeûne de 24 heures après l'éclosion reste minime (Pinchasov et Noy 1993) alors qu'un jeûne de 48 heures provoque une perte de poids du poussin d'environ $10 \%$ de son poids à l'éclosion (Pinchasov et Noy 1993, Noy et Sklan 1998c). Cet écart de poids vif est notable sur un pas de temps aussi court sachant que le gain de poids en 48 heures de vie d'un poussin alimenté rapidement après sa naissance est en moyenne de $10 \mathrm{~g}$ ce qui représente $20 \%$ de son poids à l'éclosion (Pinchasov et Noy 1993 ). Des données récentes (non publiées) obtenues dans notre équipe, montrent que le poids d'un poussin de type chair augmente d'au moins 35 $\%$ entre sa naissance et l'âge de 2 jours.

Dès l'ingestion du premier aliment, la vitesse de croissance est semblable chez des poussins alimentés après un jeûne et des poussins alimentés précocement (Sklan et Noy, 2000). Néanmoins, l'écart de poids vif dû au jeûne est

\section{L 'écart de poids entre poussins alimentés dès I'éclosion ou après un jeûne de 48 h existe encore à 21 jours d'âge.}


Figure 6. Effets sur le poids vif d'une alimentation précoce ou décalée de 34 heures. Adapté de Sklan et Noy 1999a.

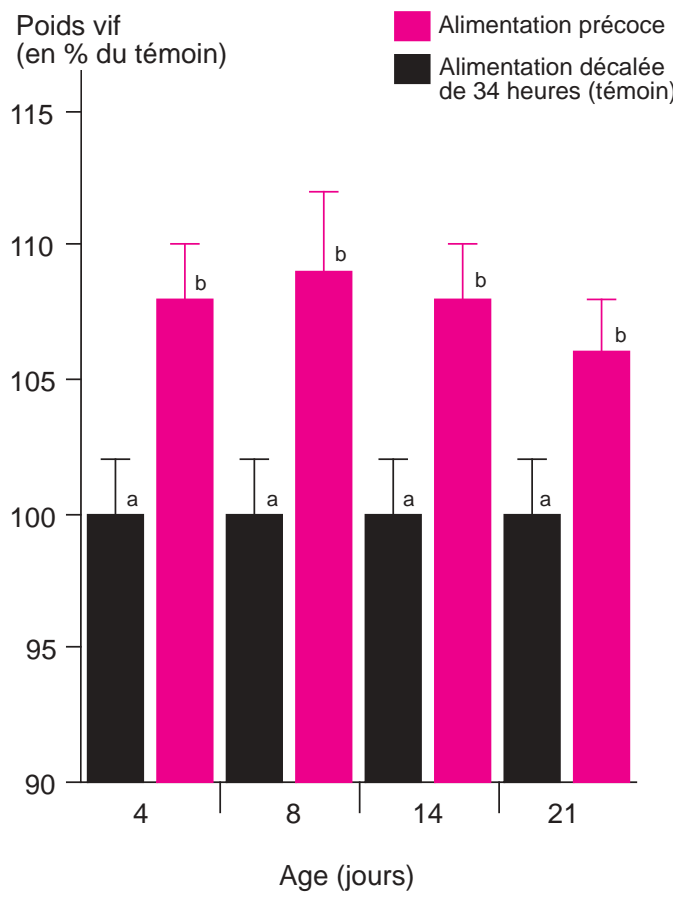

maintenu à court et long termes (figure 6). Un apport décalé d'eau et d'aliment de 34 ou 36 heures après la naissance réduit le poids des poulets à 40 jours de 100 à $200 \mathrm{~g}$ (Noy et Sklan 1998c et 1999a). Ces données suggèrent donc l'existence d'une relation inverse entre le délai d'alimentation appliqué après l'éclosion et les performances des animaux.

A l'instar du poids vif, une alimentation précoce ou décalée influence le poids et le développement des différents organes et tissus du poussin. Nous insisterons plus particulièrement sur les effets observés au niveau du système gastro-intestinal, du muscle, et du système immunitaire.

L'alimentation précoce permet un développement intense de la sphère digestive et notamment de l'intestin. Le poids de celui-ci est multiplié par deux durant les premières 48 heures de vie. La croissance de l'intestin est réduite par le jeûne post éclosion, mais un apport d'aliment décalé de 48 heures ne modifie pas ce processus de croissance et on mesure toujours une augmentation de $60 \%$ du poids de l'intestin pendant cette période (Sklan et Noy 2000 ; figure 7). La première ingestion rétablit une vitesse de croissance similaire à celle des animaux nourris dès la naissance.

La vitesse de résorption du résidu vitellin, reflet de la maturité des fonctions digestives, serait plus élevée chez les poussins nourris précocement (Noy et al 1996 ; figure 8). Ce phénomène est dû en partie à une activité péristaltique plus intense chez ces animaux, permettant un passage plus efficace du liquide vitellin par le canal de Meckel. Par ailleurs, l'augmentation des activités des enzymes pancréatiques survient consécutivement à la prise alimentaire (figure 9). Durant la période de jeûne, les activités trypsique et amylasique restent, en l'occurrence, plus faibles que celles
Figure 7. Effet d'une alimentation précoce (immédiatement après l'éclosion) ou décalée (48 h) sur le poids de l'intestin pendant la première semaine de vie (moyenne de 4 animaux par groupe). Adapté de Sklan et Noy 2000.

Poids de l'intestin $(\mathrm{g})$

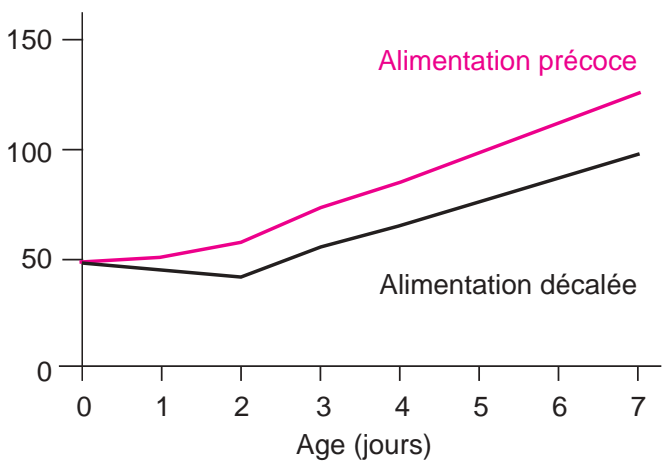

Figure 8. Effet d'une alimentation précoce (immédiatement après l'éclosion) ou décalée (96 h) sur la résorption du contenu vitellin pendant la première semaine de vie (moyenne de 20 animaux par groupe). Adapté de Noy et al 1996

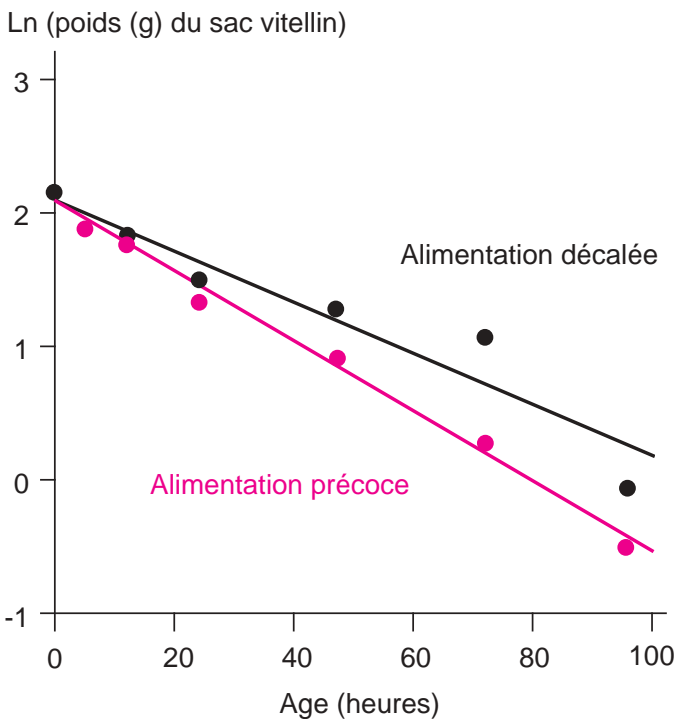

mesurées chez les poussins alimentés précocement chez lesquels elles sont augmentées dès le premier jour de vie.

L'apport décalé d'aliment après la naissance ralentit le développement des villosités intestinales (figure 10) et modifie leur morphologie (Uni et al 1998). Ces altérations, qui sont la conséquence du manque de substrat nécessaire pour une bonne prolifération cellulaire, diminuent la surface d'absorption des nutriments.

Ainsi, I'aliment constitue à lui seul un stimulus essentiel au développement du système digestif (Dibner et al 1996, Dibner 1997, Nir 1998). Un retard de la croissance du tractus gastro-intestinal expliquerait en grande partie le retard de croissance des poussins décrit précédemment (Lilja 1997).

A court et plus long termes, le poids du muscle pectoral est significativement plus faible chez les poussins alimentés en différé après l'éclosion par rapport aux poussins alimentés immédiatement (Noy et Sklan 1999a, 
Figure 9. Effet d'une alimentation précoce (immédiatement après l'éclosion) ou décalée (48h) sur les activités des enzymes digestives dans le contenu intestinal pendant la première semaine de vie (moyenne de 4 animaux par groupe). Adapté de Sklan et Noy 2000.

Les mesures d'activité des enzymes pancréatiques sont réalisées selon les technique décrites par Belfrage et Vaughau (1969, lipase), Sklan et Halevy (1985, trypsine) et Pinchasov et Noy (1994, amylase).

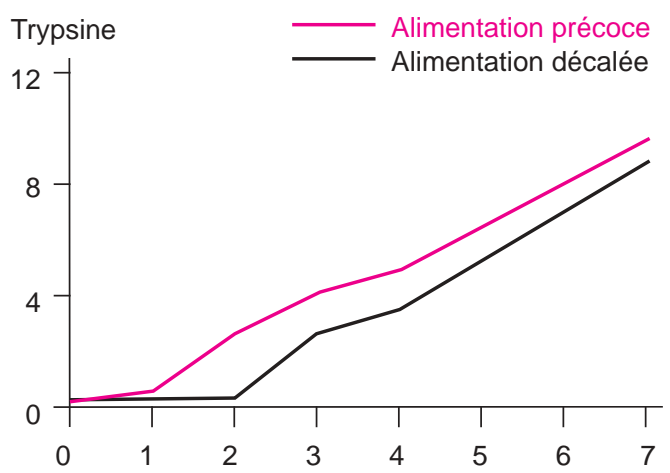

Amylase
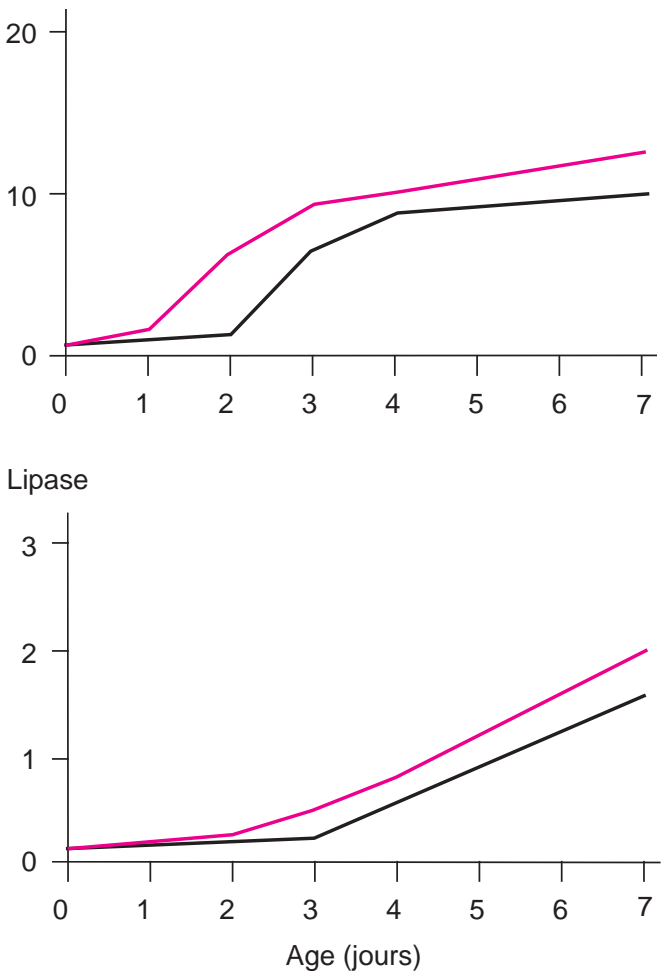

Halevy et al 2000 ; figure 11). L'apport décalé d'aliment influence également la morphologie du muscle : modification de la taille des fibres musculaires et décalage dans le temps de leur maturation. Ce décalage de la croissance musculaire ne serait pas dû à une prolifération insuffisante des cellules satellites car, apparemment, le nombre de cellules par gramme de muscle tend à être plus élevé chez les animaux alimentés 48 heures après l'éclosion que chez ceux alimentés précocement (Halevy et al 2000). Cependant, ce résultat paraît surprenant et nous ne pouvons pas exclure la possible existence d'une interaction entre l'état physiologique des animaux (à jeun ou alimentés) et le rendement de la technique d'isolement des celIules. La capacité à proliférer des cellules satel-
Figure 10. Impact de l'alimentation décalée (36 h) sur le volume des villosités intestinales du poussin nouveau-né. Valeurs moyennes de 10 villosités adjacentes chez 5 animaux différents, exprimées en pourcentage des valeurs obtenues chez les animaux nourris immédiatement après l'éclosion. Adapté de Uni et al 1998.
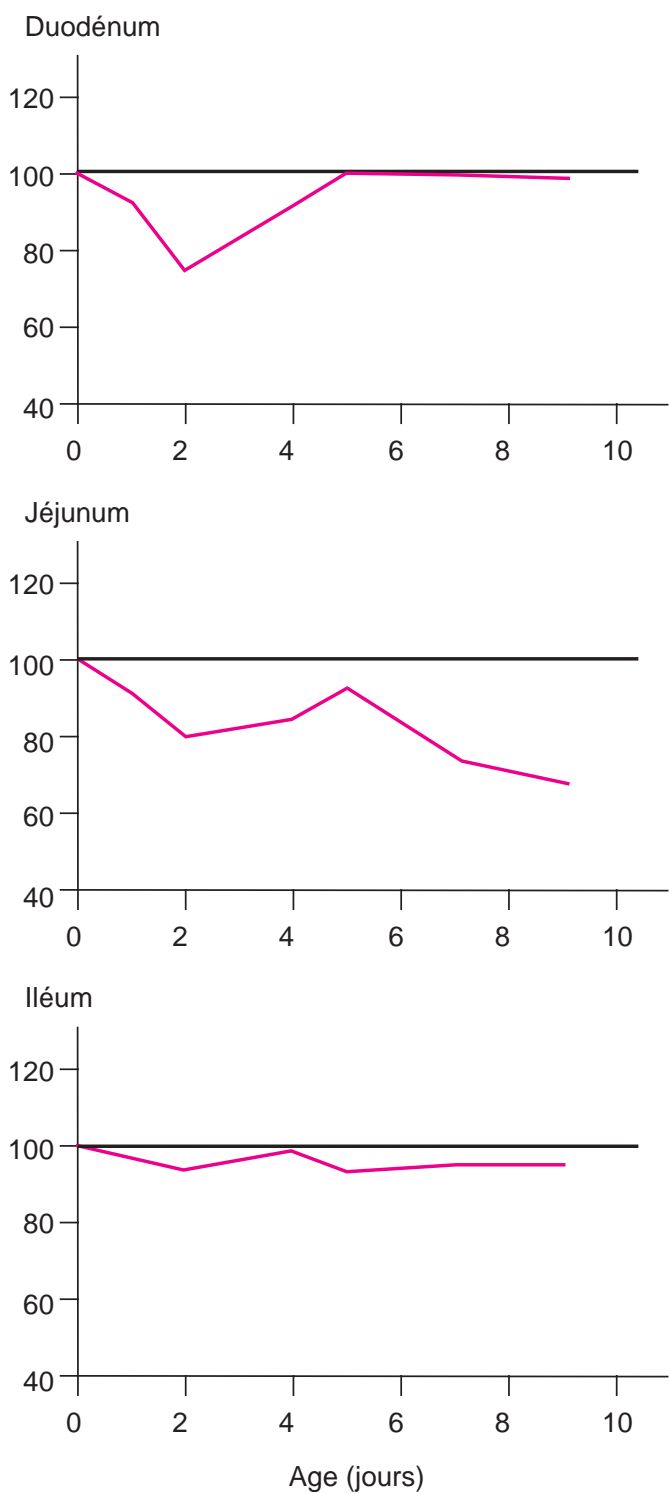

Le retard de croissance et de maturation du tractus digestif explique en grande partie le retard de croissance des poussins alimentés a près 2 jours de jeûne.

lites est négligeable chez les poussins en période de jeûne et il semblerait qu'elle ne soit stimulée qu'une fois les poussins nourris. Malgré cette induction décalee, une activité mitotique comparable à celle des cellules satellites issues de poussins alimentés précocement n'est pas retrouvée. Toutefois, dès l'âge de 3 jours, l'activité mitotique est légèrement supérieure pour les cellules des poussins nourris en différé (Halevy et al 2000). Sachant l'importance des deux premiers jours de vie dans le développement musculaire, un tel retard de croissance ne pourrait être compensé que par une capacité à proliférer exacerbée dès le début de l'alimentation et maintenue pendant quelques jours, ce qui n'est pas le cas ici.

Le jeûne post éclosion interfère également sur la croissance des tissus lymphoïdes qui présentent un poids inférieur à celui mesuré chez les poussins nourris précocement (Dibner et al 1998b). Ces différences de poids 
Figure 11. Effets d'une alimentation décalée (34 h) ou précoce (immédiatement après l'éclosion) sur le poids vif et le poids du muscle pectoral à l'abattage à 39 jours d'âge. Adapté de Noy et Sklan 1999a.

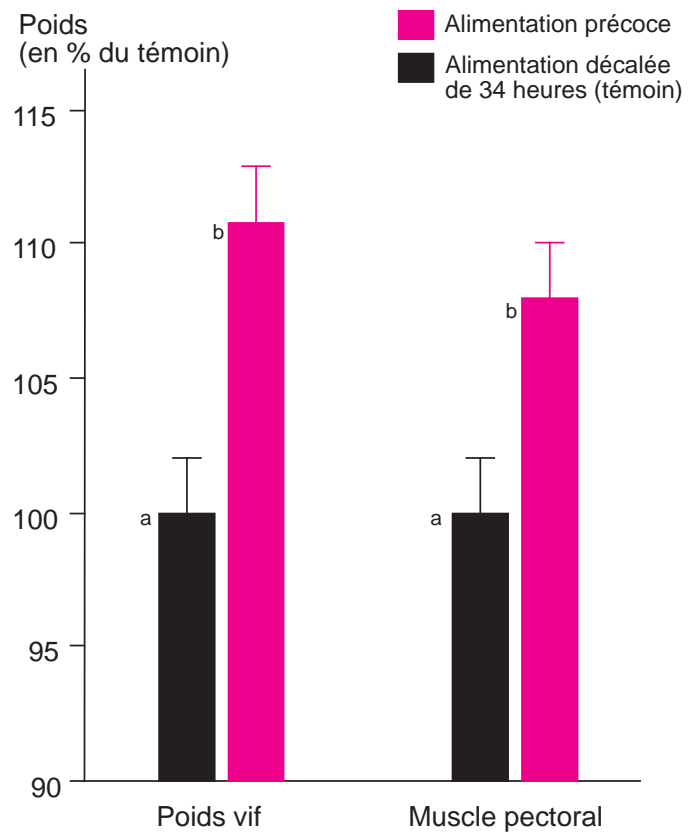

Figure 12. Effets d'une alimentation précoce (immédiatement après l'éclosion) ou décalée (48 h) sur le poids de la bourse de Fabricius et la sécrétion biliaire d'immunoglobulines de classe $A$ (mesurée par la technique Elisa). Les valeurs correspondent à la moyenne de 4 animaux. Adapté de Dibner et al $1998 b$.

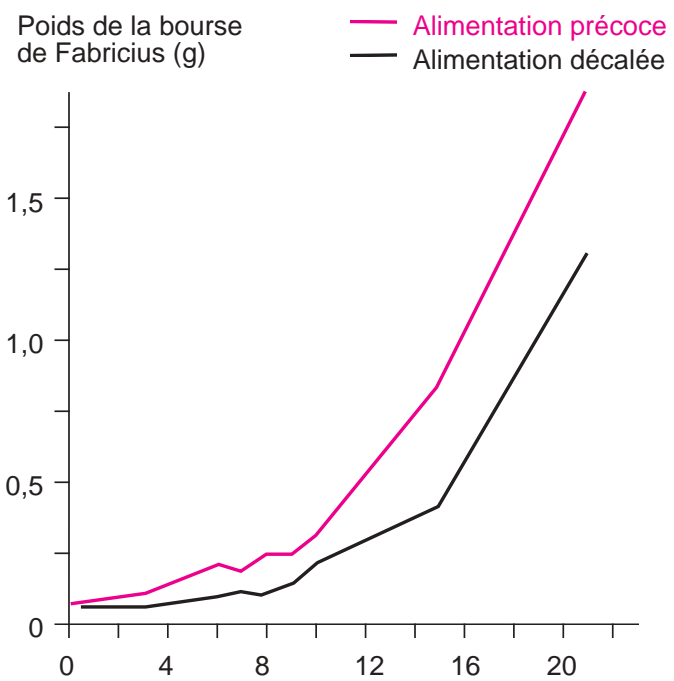

Sécrétion d'lgA (DO)

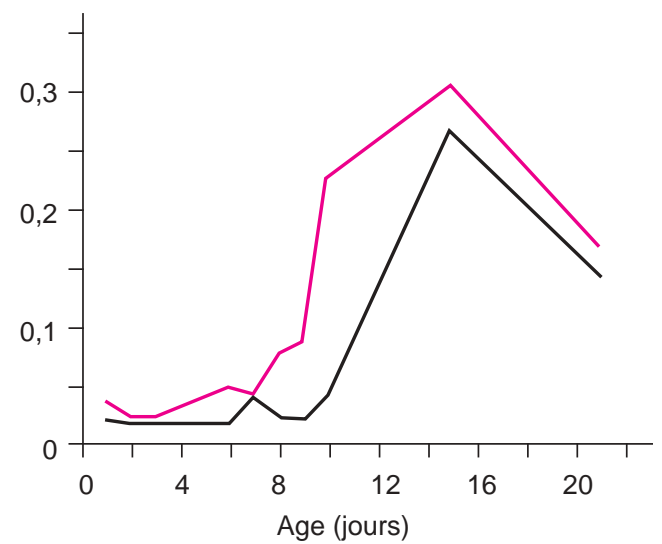

sont maintenues durant le reste de la vie des animaux (figure 12). Les capacités de défense du poussin sont amoindries face aux agents pathogènes. Le jeûne agit sur le développement du système immunitaire en général selon trois voies (Dibner et al 1998b). Les particules alimentaires et non alimentaires ingérées, qui constituent une importante batterie d'antigènes, ne sont pas exposées au poussin. La diversité du pool d'immunoglobulines produites en est, de ce fait, affectée. De plus, le jeûne stimule la sécrétion de corticostérone, hormone connue pour son puissant effet inhibiteur de la prolifération des cellules immunitaires. Enfin, dans le cas de carence lors d'un jeûne supérieur à 24 heures, le poussin dégrade les immunoglobulines maternelles présentes dans le résidu vitellin pour produire ses propres protéines nécessaires à sa survie. Inversement, une alimentation précoce induit une augmentation du poids de la bourse de Fabricius (figure 12) et une prolifération plus intense des lymphocytes. L'amélioration des capacités de défense du poussin se traduit par une production plus précoce et plus importante d'immunoglobulines de classe A spécialement impliquées dans la réponse immunitaire au niveau des muqueuses des systèmes digestif et respiratoire, principales voies de pénétration des pathogènes (figure 12).

Un délai d'alimentation appliqué après l'éclosion retarde la croissance générale du poussin. Ce phénomène ne semble pas être réversible. Un tel retard de croissance suggère une baisse de la rentabilité du poussin d'autant plus marquée que le développement du muscle pectoral est largement influencé par le délai d'alimentation.

\section{Conclusion}

La recherche d'une meilleure rentabilité des poulets de chair ne consiste plus à maximiser la vitesse de croissance. L'élaboration de nouvelles pratiques alimentaires permettant de mieux maîtriser la courbe de croissance afin de réduire la fréquence d'apparition de troubles locomoteurs et métaboliques, en freinant le développement entre 1 et 3 semaines d'âge, va dans ce sens. En revanche, il semble souhaitable de stimuler la croissance lors des premiers jours de vie du fait de ses conséquences sur le développement du fonctionnement du tube digestif et sur la mise en place des capacités cellulaires de croissance du muscle pectoral et des défenses immunitaires.

La réduction du délai entre l'éclosion et la première alimentation est un objectif prioritaire car les réserves vitellines ne constituent pas une réserve suffisante pour les poulets à croissance rapide. Le retard de développement induit par un délai de l'alimentation après l'éclosion semble être durable. Une première approche expérimentale en cours à la Station de Recherches Avicoles (INRA, Nouzilly) montre par exemple que, six jours après l'éclosion, le retard de développement du muscle pectoral n'est pas compensé. De plus, les effets du délai d'alimentation sur la qualité de la viande après abbatage ne sont pas connus. II reste également à trouver des moyens pratiques pour réduire le délai d'alimentation après 
I'éclosion. L'alimentation dans les boites de transport est encore peu utilisée et réduit seulement de quelques heures le délai. Par ailleurs, il reste à définir si cette réduction du délai d'alimentation a un effet ou non sur les performances des animaux. Enfin, la composition des aliments à donner au très jeune poussin mérite également des investigations car les quelques résultats publiés ne correspondent pas aux normes classiquement pratiquées.

\section{Remerciements}

Les auteurs remercient Sandrine Cassy pour son aide essentielle dans la préparation de ce manuscrit.

\section{Références}

Acar N., Sizemore F.G., Leach G.R., Wideman R.F.J r Owen R.L." Barbato G.F., 1995 . Growth of broiler in response to feed restriction to reduce ascites. Poult. Sci., 74, 833-843.

Applegate T., Lilburn M.S., 1996. Characteristics of changes in yolk sac and liver lipids during embryonic and early posthatch development of turkey poults. Poult. Sci., $75,478-483$.

Ballay M., Dunington E.A., Gross W.B., Siegel P.B., 1992. Restriction feeding and broiler performance: age at initiation and length of restriction. Poult. Sci., 71, 440-447.

Belfrage P., Vaughan M., 1969. Simple liquid-liquid partition for isolation of labelled oleic acid from mixtures of triglycerids. J. Lipid. Res., 10, 341-344.

Chamblee T.N., Brake J.D., Schultz C.D., Thaxton J.P., 1992. Yolk sac absorption and initiation of growth in broiler. Poult. Sci., 71, 1811-1816.

Del Castillio J.R., Rajendran R.V.M., Binder H.J ., 1991. Apical membrane localization of ouabain sensitive $\mathrm{K}+$ activated ATPase activities in rat distal colon. Am. J. Physiol., 261, G1005-G1010.

Dibner J.J., 1997. Early development of the digestive tract and the nutritional implications. Poult. Digest, August 16-19.

Dibner J. ., Kitchell M.L., Atwell C.A., Ivey F.J., 1996. The effect of dietary ingredients and age on the microscopic structure of the gastrointestinal tract in poultry. J. Appl. Poultry Res., 5, 70-77.

Dibner J . ., Knight C.D, Ivey F.J ., 1998a. The feeding of the neonatal poultry. World Poult. Ści., vol. 17, 5, 36-40.

Dibner J. Knight C.D., Kitchwell M.L., Atwell C.A. Downs A.C., Ivey F.J., 1998b. Early feeding and development of the immune system in neonatal poultry. J. Appl. Poultry Res., 7, 425-436

Duclos M., Remignon H., 1996. Développement musculaire des poulets issus de lignées à croissance rapide et lente. INRA Prod. Anim., 9, 224-226.

Duclos M. Chevalier B. Remignon H., Ricard F.H. Goddard C., Simon J., 1996. Divergent selection for high or low growth rate modifies the response of muscle cells to serum or insulin-like growth factor-I in vitro. Growth Regulation., 6, 176-184

Fanguy R.C., Misera L.K., Vo K.V., Blohowiak C.C., Krueger F., 1980. Effect of delayed placement on mortality and growth performance of commercial broiler. Poult. Sci., 59, 1215-1220.

Goddard C., J ohnson R., Gilhooley H.J., Gardner J.O. Gray A., Wilkie R.S., Butterwith S.C., 196. Decreased muscle cell proliferation in chicks with a deletion in the GH receptor gene. J. Mol. Endocrinol., 17, 67-78.

Halevy O., Lerman O., 1993. Retinoic acid induces adult muscle cell differentiation mediated by the retinoic acid receptor a. J. Cell. Physiol., 154, 566-572.

Halevy O., Geyra A., Barak M., Uni Z., Sklan D., 2000. Early posthatch starvation decreases satellite cell proliferation and skeletal muscle growth in chicks. J. Nutr., 130, 858-864.

Hurwitz S., Weiselberg M., Eisner U., Bartov I. Riesenfeld G, Sharvit M., Niv A., Bornstein S., 1980. The energy requirements and performance of growing chickens and turkey as affected by environmental temperature. Poult. Sci., 75, 2290-2299.

J in S.H., Corless A., Sell J.L., 1998. Digestive system development in post-hatch poultry. World Poult. Sci., 54 335-345.
J ones G.P.D., 1995. Manipulation of organ growth by early-life food restriction: its influence on the development of ascites in broiler chickens. Br. Poult. Sci., 36, 135-142.

Kang C.W., Sunde M.L., Swick RW., 1985. Growth and protein turnover in the skeletal muscles of broiler chicks. poult. Sci., 64, 370-379.

Krogdahl A., 1985. Digestion and absorption of lipids in poultry. J. Nutr., 115, 675-685.

Larbier M., Leclercg B., 1991. Nutrition et alimentation des volailles. INRA Editions, Paris, 335 pages.

Leslie G.A., 1975. Ontogeny of the chicken humoral immune system. Am. J. Vet. Res., 36, 482-485.

Leterrier C., Constantin P., 1996. Reducing the occurrence of varus-valgus deformations in broiler chickens
with a low energy diet or an increasing lighting shedule. Arch. Geflügelk, 60, 181-187.

Leterrier C., Rose N., Constantin P., Nys Y., 1998 Reducing growth of broiler chickens with a low energy diet does not improve cortical bone quality. Br. Poult. Sci., 39, 24-30.

Lilburn M.S., 1998. Practical aspects of early nutrition for poultry. J. Appl. Poultry Res., 7, 420-424.

Lilja C., 1983. A comparative study of postnatal growth and organ development in some species of birds. Growth 47, 317-339.

Lilja C. 1997. On the pattern of organ growth and organ development in some species of birds. Growth, 47, 317-339.

Lott B.D., Branton S.L., May J.D., 1996. The effect of photoperiod and nutrition on ascite incidences in broilers. Avian Dis., 40, 788-791.

Mitchell R.D., Burke W.H., 1995. Posthatching growth and pectoralis muscle development in broiler strain chic kens, bantam chickens and the reciprocal crosses between them. Growth Dev. Aging, 59, 149-161.

Moran E.T.J r., 1985. Digestion and absorption of carbohydrates in fowl and events through perinatal development. J. Nutr., 115, 665-674.

Moss F.P. 1968. The relationship between the dimensions of the fibres and the number of nuclei during normal growth of skeletal muscle in the domestic fowl. Am. J. Anat., 122, 555-564.

Murakami H., Akiba Y., Horiguchi M., 1992. Growth and utilisation of nutrients in newly-hatched chick with or without removal of residual yolk. Growth Dev. Aging, 56, 75-84.

Nir I., 1998. Interaction of genetic stocks, growth rate, feeding regime and metabolics diseases. 10th European poultry conference. J erusalem (Israel), 123 pages.

Nir I., Nitsan Z., Mahagna M., 1993. Comparative growth and development of the digestive organs and of some enzymes in broiler and egg type chicks after hatching. $\mathrm{Br}$. poult. Sci., 34, 523-532.

Nitsan Z., Ben-Avraham G., Zoref Z., Nir I., 1991a. Growth and development of the digestive organs and some enzymes in broiler chicks after hatching. Br. Poult. Sci., 32, 515-523.

Nitsan Z., Dunnington E A Siegel P. B. 1991b. Organ growth and digestive enzyme levels to fifteen days of age in lines of chickens differing in body weight. Poult. Sci., 70, 2040-2048

Noble R.C., Ogunyemi D., 1989. Lipids changes in the residual yolk and liver of the chick immediately after hatching. Biol. Neonate, 56, 228-236.

INRA Producti ons Ani males, octobre 2001 
Noy Y., Pinchosov Y., 1993. Effect of a single posthatch intubation of nutrients on subsequent performance of broiler chicks and turkey poults. Poult. Sci., 72, 1861-1866.

Noy Y., Sklan D., 1995. Digestion and absorption in the young chick. Br. Poult. Sci., 74, 366-373.

Noy Y., Sklan D., 1996. Uptake capacity in vitro for glucose and methionine and in situ for oleic acid in the proximal small intestine of posthatch chicks. Poult. Sci., 75, 9981002.

Noy Y., Sklan D., 1997. Posthatch development in poultry. J. Appl. Poultry Res., 6, 344-354.

Noy Y. Sklan D. 1998a. Yolk utilisation in hatching birds. 10th European symposium on poultry nutrition. J erusalem, Israël, 123 pages.

Noy Y., Sklan D., 1998b. Yolk utilisation in the new-hatched chick. Br. Poult. Sci., 39, 446-451.

Noy Y., Sklan D., 1998c. Metabolic responses to early nutrition. J. Appl. Poultry Res., 7, 437-451

Noy Y., Sklan D., 1999a. Different types of early feeding and performance in chicks and poults. J. Appl. Poultry Res., 8, 16-24.

Noy Y., Sklan D., 1999b. Energy utilization in newly chicks. Poult. Sci., 78, 1750-1756.

Noy Y., Uni Z., Sklan D., 1996. Routes of yolk utilisation in the new-hatched chick. Br. Poult. Sci., 37, 987-996.

NRC : National Research Council, 1994. Nutrient requirements of poultry. 9th rev. ed. National Academy press, Washington, DC.

Perey D.Y., Bienenstock J ., 1973. Effects of bursectomy and thymectomy on ontogeny of fow I IgA, IgG and IgM. J. Immun., 111, 633-637.

Picard M., Siegel P., Leterrier C., Geraert P.A., 1999. Diluted started diet, growth performance, and digestive tract development in fast- and slow-growing broilers. J. Appl. Poultry Res., 8, 122-131.

Pinchasov Y., Noy Y., 1993. Comparison of posthatch holding time and subsequent early performance of broiler chicks and turkey poults. Br. Poult. Sci., 69, 1718-1723.

Pinchasov Y., Noy Y., 1994. Early postnatal amylolysis in the gastrointestinal tract of turkey poults (Meleagris gallopavo). Comp. Biochem. Physiol., 106, 221-225.

Plavnik I., Hurwitz S., 1985. The performance of broiler chicks during and following a severe feed restriction at an early age. Poult. Sci., 64, 348-355.

Plavnik I., McMurtry J.P., Rosebrough R.W., 1986. Effects of early feed restriction in broilers. I: Growth performance and carcass composition. Growth, 50, 68-76.

Puvadolpirod S., Thompson I.R., Green I ., Latour M.A. Thaxton J.P., 1997. Influence of yolk on blood metabolites in perinatal and neonatal chickens. Growth Dev. Aging, 61, in perinat.

Qureshi M.A., Havenstein G.B., 1994. A comparaison of the immune performance of a 1991 commercial broile with a 1957 randombred strain when fed 'typical' 1957 and 1991 broiler diets. Poult. Sci., 73, 1805-1812
Ricklefs R.E., 1985. Modification of growth and development of muscles of poultry. Poult. Sci., 64, 1563-1576.

Romanoff A.L, 1960. The avian embryo. Structural and functional development. The Macmillan company, New York (USA), 1305 pages

Sanchez A., Plouzeau M., Rault P., Picard M., 2000 Croissance musculaire et fonction cardio-respiratoire chez le poulet de chair. INRA Prod. Anim., 13, 37-45.

Sayegh C.E. Demaries S.L., Pike K.A., Friedman J.E Ratcliffe M.J., 2000. The chicken B-cell receptor complex and its role in avian B-cell developpement. Immunol Rev. $175,187-200$

Scheideler S.E., Baughman G.R., 1993. Computerized early feed restriction programs for various strains of broilers. Poult. Sci., 72, 236-242.

Sell J.L., Angel C.R., Piquer F.J., Mallarino E.G., AlBatshan H.A., 1991. Developmental' patterns of selected characteristics of the gastrointestinal tract of young turkeys. Poult. Sci., 70, 1200-1205.

Siegel P.B., Dunnington E.A., 1998. Ressource allocations: growth and immune responses.10th European poultry conference. J erusalem (Israel), 123 pages.

Sklan D., Halevy O., 1985. Protein digestion and absorption along the ovin gastrointestinal tract. J. Dairy Sci., 68 1676-1681.

Sklan D., Noy Y., 2000. Hydrolysis and absorption in the small intestines of posthatch chicks. Poult Sci.,79, 13061310.

Turro I., Dunnington E.A., Nitsan Z., Picard M., Siege P.B., 1994. Effect of yolk sac removal at hatch on growth and feeding behavior on lines of chickens differing in body weight. Growth Dev. Aging, 58, 105-112.

Uni Z., 1999. Functional development of the small intestine in domestic birds: cellular and molecular aspects. Poultry and avian Biol. Rev., 10, 167-179.

Uni Z., Noy Y., Sklan D., 1995a. Development of the small intestine in heavy and light-strain chicks before and after hatching. Br. Poult. Sci., 36, 63-71.

Uni Z., Noy Y., Sklan D., 1995b. Posthatch changes in morphology of the small intestine in heavy and light-strain chicks. Poult. Sci., 74, 1622-1629.

Uni Z., Ganot S., Sklan D., 1998. Posthatch development of mucosal function in the broiler small intestine. Poult. Sci., 77, 75-62.

Uni Z., Noy Y., Sklan D. 1999. Posthatch development of small intestinal function in the poult. Poult. Sci., 78, 215 222.

Whittow G.C., 1999. Sturkie's avian physiology (5ème edition). Academic press San Diego (USA), 685 pages.

Zubair A.K., Leeson S., 1996. Compensatory growth in the broiler chicken: a review. World Poult. Sci. J., 52, 189 201.

Zulkifli I., Dunnington E.A., Gross W.B., Siegel P.B. 1994. F ood restriction early or later in life and its effect on adaptability, disease resistance, and immunocompetence of heat-stressed dwarf and nondwarf chickens. Br. Poult. Sci., 35, 203-213.

\section{Abstract}

Posthatch feeding and early development in broiler chicks.

For the last ten years, early nutrition of newborn chicks has attracted increasing interest due to its long term effects on broiler performances. Residual yolk is quickly resorbed. It represents a small contribution ( 1 day) to nutritional requirements induced by the intensive growth of digestive organs and function and of the pectoral muscle during the two to three days post-hatch. Hatching and transportation procedures delay the feeding of chicks by 10 to 60 hours from one individual to another. Several published studies conclude that this starvation at a critical moment may have long lasting negative effects on growth and immune response of chicks. The few published studies on early life nutrition suggest that regular diet might be too rich in lipids and too poor in proteins. Moreover, it is necessary to slow down growth between one and three weeks of age in order to reduce leg and metabolic disorders later on Nutritional tuning for young broilers might include three phases: an early stimulation during the first week, a mild restriction from one to three weeks, followed by a predominantly economic oriented optimisation after three weeks of age. Within such a pattern, the effects of early stimulation by an earlier or/and wiser feeding of chicks on meat quality and overall performances require precise quantification

BIGOT K., TESSERAUD S., TAOUIS M., PICARD M. 2001. Alimentation néonatale et développement précoce du poulet de chair. INRA Prod. Anim., 14, 219-230. 